\title{
Iodine Levels in Pregnant Women with Hyperemesis Gravidarum
}

\author{
Seyma Banu ARSLANCA ${ }^{*}$, Vakkas KORKMAZ ${ }^{2}$, Tufan ARSLANCA ${ }^{3}$, Figen BESYAPRAK ${ }^{4}$, Adil BARUT $^{5}$ \\ Ankara, Turkey
}

\section{ABSTRACT}

OBJECTIVE: lodine deficiency is a commonly seen problem and associated with pregnancy complications. In this study, we aimed to evaluate urinary iodine status in pregnant women with hyperemesis gravidarum

STUDY DESIGN: A total of 121 women experiencing singleton pregnancies between 6 and 18 weeks of gestation were included in the study. The participants were divided into two groups; group 1 comprised 81 healthy pregnant women, and group 2 comprised 40 pregnant women with Hyperemesis Gravidarum.

RESULTS: Urinary iodine levels were found to be significantly higher in healthy pregnant women than women with Hyperemesis Gravidarum $(p=0.008)$. Urinary iodine was significantly correlated with the urinary ketone $(r=-0.252, p=0.005)$ and FT3 $(r=-0.190, p=0.037)$.

CONCLUSION: In pregnant women with hyperemesis gravidarum, oxidative stress was increased, urinary iodine levels were significantly low and negatively correlated with disease severity. Thus, Iodine replacement might be essential to prevent pregnancy complications.

Keywords: Hyperemesis gravidarum, Oxidative stress, Urinary iodine

Gynecol Obstet Reprod Med 2021;27(1):6-10

\section{Introduction}

Hyperemesis gravidarum (HEG) is a condition that occurs in $0.3-2.0 \%$ of pregnancies and which is characterized by severe nausea and vomiting accompanied by weight loss or dehydration, causing a decrease in nutrient antioxidants and a loss of crucial elements and minerals (1). Furthermore, HEG is associated with increased healthcare usage, hospitalization, absence from work and decreased quality of life during preg-

${ }^{I}$ Department of Obstetrics and Gynecology, Ankara University Faculty of Medicine, Ankara, Turkey

${ }^{2}$ Department of Obstetrics and Gynecology, Zekai Tahir Burak Training and Research Hospital, Ankara, Turkey

${ }^{3}$ Department of Obstetrics and Gynecology, Ufuk University, Ankara, Turkey ${ }^{4}$ Department of Obstetrics and Gynecology, Yenimahalle Training and Research Hospital, Ankara, Turkey

${ }_{5}^{5}$ Avcılar Murat Kölük State Hospital, İstanbul, Turkey

Address of Correspondence: Seyma Banu Arslanca

Department of Obstetrics and Gynecology,

Ankara University Faculty of Medicine

06100 Mamak, Ankara, Turkey

dr.banubozkurt@hotmail.com

Submitted for Publication: $\quad$ 02.05.2019 Revised for Publication: 16.07.2019 Accepted for Publication:

ORCID IDs of the authors:

$V K: 0000-0001-8895-6864$, FB: 0000-0002-9834-2118

04.12 .2020

SBA:0000-0003-2494-3372,

TA: 0000-0001-9686-1603,

$A B$ : 0000-0003-0146-0474

\begin{tabular}{c|c}
\hline Quick Response Code: & Access this article online \\
\cline { 2 - 2 } & $\begin{array}{c}\text { Website: www.gorm.com.tr } \\
\text { e- mail: infogorm.com.tr }\end{array}$ \\
\cline { 2 - 2 } & DOI:10.21613/GORM.2019.968 \\
\hline
\end{tabular}

How to cite this article: Arslanca SB. Korkmaz V. Arslanca T. Besyaprak F. Barut A. Iodine Levels in Pregnant Women with Hyperemesis Gravidarum Gynecol Obstet Reprod Med 2021;27(1):6-10 nancy (2). It is also associated with maternal weight loss and electrolyte imbalance and causes adverse perinatal outcomes (3), including lower birth weight, preterm delivery, and congenital anomalies of the central nervous system (4).

Iodine is an essential nutrient during pregnancy. The vast majority of ingested iodine is excreted in the urine, so urinary 1odine is a sensitive indicator of recent iodine intake (5). Iodine function as an antioxidant and it has been suggested that it can function directly as an electron donor and compete for linking sites with free radicals (6). Iodine deficiency (ID) may take part in the antioxidant equilibrium, and this makes the tiers of oxidative stress, leading to the development of complications during pregnancy (7). The severe ID may cause gross mental retardation, deaf-mutism, and spasticity in the fetus (8). Treatment of ID may prevent perinatal mortality and can also improve the motor and cognitive development of the fetus (4). In light of this, we hypothesized that ID might contribute to the increased level of oxidative stress in women with hyperemesis gravidarum.

Previous studies have found relationships between ID in pregnancy and disorders such as fetal growth retardations, perinatal, and infant mortality; however, ID in hyperemesis gravidarum has not been previously investigated (9-11). The aim of this study was, therefore, to evaluate urinary iodine levels in pregnant women with HEG.

\section{Materials and Methods Study Design and Eligibility}

This prospective study was conducted at Yenimahalle 
Education and Research Hospital after Ethics committee approval was received with the protocol number 2018/12. The informed written consent was obtained from each of the participants. The study was conducted with the Declaration of Helsinki. A total of 121 women experiencing singleton pregnancies between 6 and 18 weeks of gestation and who were attending a pregnancy follow-up polyclinic were enrolled in the study. The participants were divided into two groups; group 1 comprised 81 healthy pregnant women who were randomly selected by a computer program and matched to group 2 comprised 40 pregnant women consecutively with HEG in terms of age, body mass index (BMI) and gestation period. Women with pregnancies over 20 weeks, eating disorders, psychiatric diseases, an indication of cigarette smoking, any vitamin or mineral supplements or medications containing iodine, evidence of any inflammatory disease, thyroid disease, or multiple and molar pregnancies were excluded.

\section{Definitions}

Diagnosis of HEG was defined by having at least two of the following symptoms: (a) weight loss of more than $2.25 \mathrm{~kg}$; (b) existence of ketonuria positivity $>1+$, assessed by dipstick in a random urine specimen; (c) presence of hyponatremia (sodium $<134 \mathrm{mEq} / \mathrm{L}$ ) or hypokalemia (potassium $<3.0$ $\mathrm{mEq} / \mathrm{L}$ ) which necessitated intravenous fluid replacement; and (d) more than two visits to the Obstetric Emergency Department due to HEG symptoms (12).

Each patient's gestation age was calculated according to her last menstrual cycle. For patients who did not know their last menstruation date, gestation weeks were calculated by dating scan. If the two calculations were discordant, the gestation age calculated by the dating scan was used in the study (13).

BMI was calculated as weight (in kilograms) divided by height (in meters) squared (14).

\section{Biochemical Assays}

Venous blood samples were collected in a Vacationer tube containing ethylenediaminetetraacetic acid (BD, Belliver Industrial Estate, Plymouth, UK). All of the samples were preserved at room temperature for 30 minutes to allow clotting and then centrifuged at 2,400 rpm for 10 minutes. The eligible samples were tested on the same day. Thyroid-stimulating hormone (TSH; 0.27-4.2 $\mu \mathrm{IU} / \mathrm{mL})$, free triiodothyronine (FT3; 2.04-4.4 pg/mL), free thyroxine (FT4; 0.85-1.7 ng/dL), serum sodium $(135-145 \mathrm{mEq} / \mathrm{L})$, serum potassium $(3.5-5.1$ $\mathrm{mEq} / \mathrm{L}$ ) and total beta-human chorionic gonadotropin ( $\beta$-hCG; $\mathrm{mIU} / \mathrm{mL}$ ) were analyzed using a UniCelDxl 800 Access Immunoassay System (Beckman Coulter, USA). Serum thyroglobulin $(0-55 \mathrm{ng} / \mathrm{mL})$ levels were calculated with an Immulite 2000 device using the chemiluminescence immunometric assay method. Serum gamma-glutamyltransferase (GGT) levels (0-38 U/L) were calculated with commercially available kits (Bayer, US) by using an autoanalyzer (Technicon RA-XT, Bayer, US). Urine samples were taken and gathered in storage beakers under sterile conditions. Samples measuring $5 \mathrm{~mL}$ each were divided into individual test tubes, for the deiodination of the paraffin. After darkening the room, the sealed containers were placed in a freezer, and iodine was simultaneously stored at $-18^{\circ} \mathrm{C}$ until measurement. Urine samples were measured using an inductively-coupled plasma mass spectrometry (ICP-MS) technique, using an ICPMS device (Agilent, USA) to determine I concentrations (100$700 \mu \mathrm{g} / \mathrm{L})$. Urinary ketone positivity was measured by Labstick and graded from 0 to $4+$.

\section{Statistical Analysis}

Statistical analysis was carried out using Statistical Package for the Social Sciences (SPSS) software package (Version 17.0 for Windows, SPSS Inc., Chicago, IL, USA). The distribution of the data was defined using the test of normality. Continuous variables were demonstrated as a mean \pm standard deviation (SD), and categorical variables were presented as median (minimum-maximum). Parametric data were tested using an independent-groups Student's t-test, and nonparametric data were tested with the Mann-Whitney U test. Pearson's and Spearman's correlation analyses were used to measuring the degree of associations. A p-value of $<0.05$ was considered statistically significant.

\section{Results}

The mean age of participants was $27.9 \pm 5.2$ years, and the mean BMI was $25.6 \pm 4.4 \mathrm{~kg} / \mathrm{m}^{2}$. The mean gestational age was calculated as $11.3 \pm 1.7$ weeks. The mean weight loss in group 2 was $3000 \pm 186 \mathrm{~g}$, and a median number of vomiting per day in group 2 was 4 (0-10).

Urinary iodine levels were $112.6 \pm 60.7 \mu \mathrm{g} / \mathrm{L}$ in group 1 and $84.9 \pm 33.7 \mu \mathrm{g} / \mathrm{L}$ in group $2(p=0.008$, Figure 1). GGT levels were $12.1 \pm 4.4 \mathrm{U} / \mathrm{L}$ in group 1 and $19.4 \pm 10.6 \mathrm{U} / \mathrm{L}$ in group 2 $(p=0.012$, Figure 2$)$. In addition, urinary ketone positivity was $0[0-1(+)]$ in group 1 and $2(+)[1(+) 3(+)]$ in group $2(p=$ $<0001)$; serum sodium levels were $136.4 \pm 1.3 \mathrm{mEq} / \mathrm{L}$ in group 1 and $136.5 \pm 1.2 \mathrm{mEq} / \mathrm{L}$ in group $2(p=0.006)$; serum TSH levels were $1.5 \pm 1.1 \mu \mathrm{IU} / \mathrm{mL}$ in group 1 and $1.3 \pm 0.7 \mu \mathrm{IU} / \mathrm{mL}$ in group $2(p=0.015)$; serum FT3 levels were $2.7 \pm 0.4 \mathrm{pg} / \mathrm{mL}$ in group 1 and $3.1 \pm 0.7 \mathrm{pg} / \mathrm{mL}$ in group $2(p=0.003)$; serum $\beta$ hCG levels were $75132.8 \pm 25692.4 \mathrm{mIU} / \mathrm{mL}$ in group 1 and $86509.1 \pm 31582.1 \mathrm{mIU} / \mathrm{mL}$ in group $2(p=0.001)$. A comparison of the groups is shown in table I.

In the correlation analysis, urinary iodine was significantly correlated with the urinary ketone $(r=-0.252, p=0.005)$, FT3 $(r=-0.190, p=0.037)$. There was also a significant correlation between the number of vomiting, urinary ketone $(r=0.803, p=$ $<0.001)$, serum sodium $(r=-0.213, p=0.019)$, FT3 $(r=0.232$, $p=0.1)$ and $\beta$-hCG $(r=0.004, p=0.263)$. Finally, urinary ketone levels were correlated with sodium $(r=-0.201, p=0.027)$, FT3 $(r=-0.207, p=0.023), \beta-\mathrm{hCG}(r=0.222, p=0.015)$ and GGT $(r=0.388, p=0.034)$. 


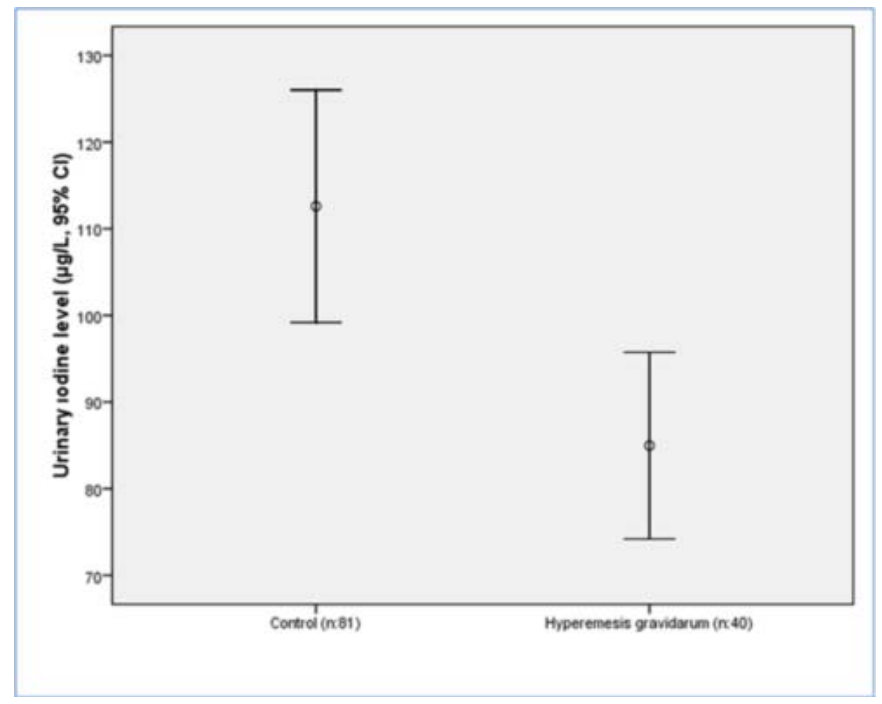

Figure 1: Comparison of urinary iodine level between the groups $(p=0.008)$

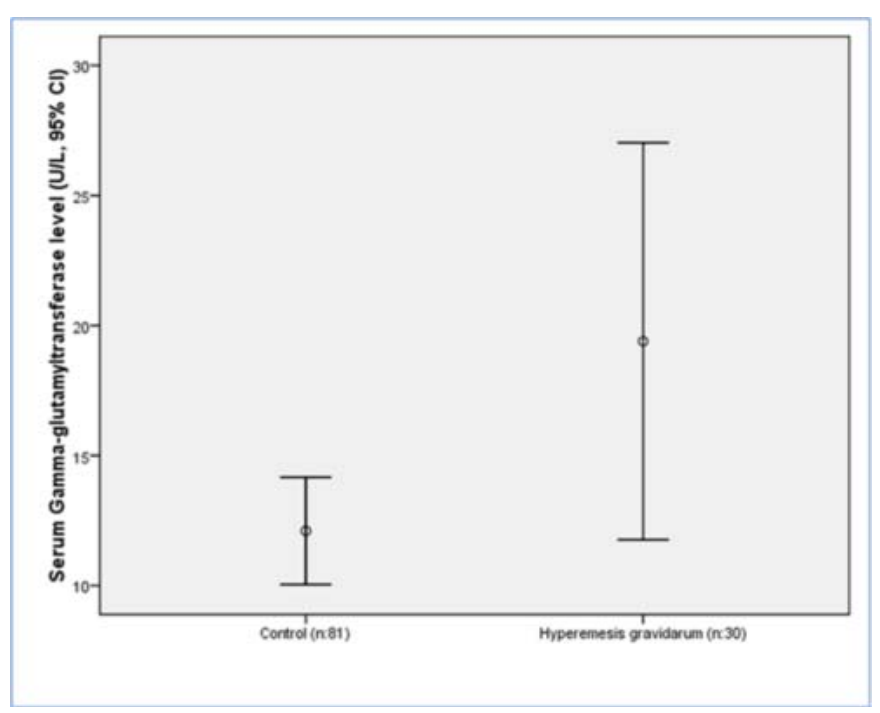

Figure 2: Comparison of Serum Gamma-glutamyltransferase between the groups $(p=0.012)$

Table I: Comparison of the groups

\begin{tabular}{|c|c|c|c|}
\hline & Group $1(n=81)$ & Group $2 \quad(n=40)$ & $p$ \\
\hline Age (Year) & $28 \pm 4.2$ & $29.1 \pm 5.3$ & NS \\
\hline BMI $\left(\mathrm{kg} / \mathrm{m}^{2}\right)$ & $26.6 \pm 3.6$ & $27.3 \pm 2.4$ & NS \\
\hline Gestational age (week) & $11.4 \pm 1.8$ & $11.1 \pm 1.4$ & NS \\
\hline Gravidity & $3(1-4)$ & $2(1-4)$ & NS \\
\hline Parity & $1(0-3)$ & $1(0-2)$ & NS \\
\hline Urinary ketone positivity & $0(0-1)$ & $2(1-3)$ & $<0.001$ \\
\hline Serum sodium (mEq/L) & $136.4 \pm 1.3$ & $136.5 \pm 1.2$ & 0.006 \\
\hline Serum potassium (mEq/L) & $4.1 \pm 0.3$ & $3.9 \pm 0.4$ & NS \\
\hline $\mathrm{TSH}(\mu \mathrm{IU} / \mathrm{mL})$ & $1.5 \pm 1.1$ & $1.3 \pm 0.7$ & 0.015 \\
\hline FT3 (pg/mL) & $2.7 \pm 0.4$ & $3.1 \pm 0.7$ & 0.003 \\
\hline FT4 (ng/dL) & $1.32 \pm 0.4$ & $1.38 \pm 0.3$ & NS \\
\hline$\beta-h C G(\mathrm{mlU} / \mathrm{ml})$ & $75132.8 \pm 25692.4$ & $86509.1 \pm 31582.1$ & $<0.001$ \\
\hline Thyroglobulin (ng/mL) & $9.8(0.3-69)$ & $8.5(0.1-33.5)$ & NS \\
\hline Urinary lodine Concentration $(\mu \mathrm{g} / \mathrm{L})$ & $112.6 \pm 60.7$ & $84.9 \pm 33.7$ & 0.008 \\
\hline Gamma-glutamyltransferase (U/L) & $12.1 \pm 4.4$ & $19.4 \pm 10.6$ & 0.012 \\
\hline
\end{tabular}

TSH: Thyroid-stimulating hormone, FT3: Triiodothyronine, FT4: Thyroxine, $\beta$-hCG: Beta-human chorionic gonadotropin, NS: Not significant

\section{Discussion}

To the best of our knowledge, this is the first study in the literature to evaluate urinary iodine levels in pregnant women with HEG. We also evaluated the relationship between oxidative stress and HEG by measuring serum GGT levels. At the end of the study, we found that group 2 urinary iodine levels were significantly low and were negatively correlated with urinary ketone levels, and serum GGT levels were also significantly high.

Although the present study is the first to assess the relationship between body iodine status and HEG, it had some crucial limitations. First, we did not perform a pilot study or calculate sample size at the beginning of the study, because there were no previous studies among this population. Second, this study was an observational investigation, and therefore, we cannot prove causality; however, there were significant differences between the groups.

In the literature, the relationship between iodine levels and pregnancy complications have been evaluated in several studies (15-17). Porterfield et al. have suggested that iodine has a crucial role in the development of thyroid hormone, which also contributes to the neurological development of fetuses. They also assert that ID causes fetal and maternal mortality. Furthermore, it causes a condition characterized by mental retardation and varying degrees of short stature, spasticity, and deaf-mutism, and increases infant mortality rates (18).

A systematic review conducted by Zimmerman et al. showed that severe ID might cause fetal and maternal hy- 
pothyroxinemia and cretinism. Thus, it may affect cognitive development in children. As a consequence, iodine should be given before or early during pregnancy to prevent these adverse effects (19). Besides, research has illustrated that ID changes trophoblast differentiation and contributes to a dysfunctional endothelium, which causes pregnancy complications (20). Similarly, Gulaboglu et al. assessed the urinary iodine concentrations of both preeclamptic and healthy pregnant woman and found that iodine concentrations were significantly lower in women with preeclampsia. Moreover, there was a positive correlation between the severity of preeclampsia and iodine. They suggest that iodine supplementation should be considered to prevent complications in pregnancy (21). In our study, we found that iodine levels were significantly lower in women with HEG, which is a pregnancy complication.

Ketonuria is characterized by the catabolism of adipose stores and can be a sign of HEG in patients who are unable to tolerate oral intake. The severity of ketonuria, as determined through a dipstick, is defined concerning the severity of HEG (22). Morali et al. conducted a study of 80 patients with HEG and found that HEG causes starvation and dehydration. These factors are crucial for the induction of liver cell injury and thus cause ketonuria. Morali et al. also concluded that ketonuria was significantly more severe in the experimental group with abnormal enzymes, implying a more severe state of starvation and dehydration (23). In the present study, we found a positive correlation between the urinary ketone and vomiting number. Furthermore, there was a significant negative correlation between ketonuria and urinary iodine. These results suggest that ID in HEG is associated with the severity of the HEG.

The ID is connected with increased oxidative stress during pregnancy (7). During gestation, there is a physiological enhancement in antioxidant activity as a response to the oxidative stress of pregnancy (24). Faith et al. found that HEG is an oxidative status and also demonstrated that antioxidant components significantly decrease in the plasma levels of HEG patients, as compared with a control group (25). In our study, GGT levels, which are a marker of oxidative stress (26), were markedly high and urinary iodine levels were significantly low in group $2(p=0.012)$. Thus, ID may have a role in increased oxidative stress in HEG patients.

\section{Conclusion}

Oxidative stress increased, and urinary iodine levels decreased in HEG patients. Iodine deficiency may furthermore contribute to increased oxidative stress. Thus, iodine replacement is crucial because it may decrease and compensate for oxidative stress in pregnant women, particularly those with HEG.

Ethics: Ethics Committee Approval: The study was approved by the Local Ethics Committee of the University of Health Sciences Yenimahalle Training and Research Hospital (approval number: 2018/05-03)
Informed Consent: Consent form was filled out by all participants.

Funding: None

Acknowledgment: None

Conflict of Interest: The authors declare that they have no conflict of interest.

Author's Contributions: SBA: Conceived and designed the analysis, collected data, wrote paper. VK: Contributed data and analysis tools. TA: Collected data and performed the analytic calculations. FB: Collected the data. AB:Contributed to sample preparation.

\section{References}

1. Kallen B, Lundberg G, Aberg A. Relationship between vitamin use, smoking, and nausea and vomiting of pregnancy. Acta Obstet Gynecol Scand. 2003;82(10):916-20.

2. Attard CL, Kohli MA, Coleman S, Bradley C, Hux M, Atanackovic $\mathrm{G}$, et al. The burden of illness of severe nausea and vomiting of pregnancy. Am J Obstet Gynecol. 2002;186(5 Suppl Understanding):S220-7. doi:10.1067/ mob.2002.122605.

3. Hod M, Orvieto R, Kaplan B, Friedman S, Ovadia J. Hyperemesis gravidarum: a review. J Reprod Med. 1994;39(8):605-12.

4. Pearce EN, Lazarus JH, Moreno-Reyes R, Zimmermann MB. Consequences of iodine deficiency and excess in pregnant women: an overview of current knowns and unknowns. Am J Clin Nutr. 2016;104(Suppl 3):918S-23S. doi: 10.3945/ajen.115.110429.

5. World Health Organization, International Council for the Control of the Iodine Deficiency Disorders, United Nations Children's Fund (WHO/ICCIDD/UNICEF). Assessment of the iodine deficiency disorders and monitoring their elimination. Geneva: World Health Organization; 2007.

6. Venturi S, Venturi M. Iodide, thyroid and stomach carcinogenesis: Evolutionary story of a primitive antioxidant? Eur J Endocrinol. 1999;140(4):371-2. doi: 10.1530/eje.0.1400371.

7. Vidal ZE, Rufino SC, Tlaxcalteco EH, Trejo CH, Campos RM, Meza MN, et al. Oxidative stress increased in pregnant women with iodine deficiency. Biol Trace Elem Res. 2014;157(3):211-7. doi: 10.1007/s12011-014-9898-6.

8. Zhao W. Li X. Xia X. Gao Z. Han C. Iodine nutrition during pregnancy: past, present, and future. Biol Trace Elem Res. 2019;188(1):196-207. doi:10.1007/s12011-0181502-z.

9. Arslanca T. Korkmaz V. Arslanca SB. Karadag B. Ergün Y. Body iodine status in women with postmenopausal osteoporosis. Menopause. 2018;25(3):320-3. doi: 10.1097/ GME.0000000000000987.

10. Zimmermann MB. The effects of iodine deficiency in pregnancy and infancy. Paediatr Perinat Epidemiol. 
2012;26 Suppl 1:108-17. doi:10.1111/j.1365-3016. 2012.01275.x.

11. Melse-Boonstra A. Jaiswal N. Iodine deficiency in pregnancy, infancy and childhood and its consequences for brain development. Best Pract Res Clin Endocrinol Metab. 2010;24(1):29-38. doi: 10.1016/ j.beem.2009. 09.002 .

12. Sullivan CA. Johnson CA. Roach H. Martin RW. Stewart DK. Morrison JC. A pilot study of intravenous ondansetron for hyperemesis gravidarum. Am J Obstet Gynecol. 1996;174(5):1565-8. doi:10.1016/s00029378(96)70607-5.

13. Martin JA. Osterman MJ. Kirmeyer SE. Gregory EC. Measuring gestational age in vital statistics data: Transitioning to the obstetric estimate. Natl Vital Stat Rep. 2015;64(5):1-20.

14. Heslehurst N. Simpson H. Ells LJ. Rankin J. Wilkinson J. Lang R. et al. The impact of maternal BMI status on pregnancy outcomes with immediate short-term obstetric resource implications: A meta-analysis. Obes Rev. 2008;9(6):635-83. doi:10.1111/j.1467-789X.2008. 00511. $\mathrm{x}$.

15. Glinoer D. The regulation of thyroid function during normal pregnancy: importance of the iodine nutrition status. Best Pract Res Clin Endocrinol Metab. 2004;18(2):133doi: 10.1016/j.beem.2004.03.001.152.

16. Mills JL. Ali M. Buck Louis GM. Kannan K.Weck J. Wan Y. et al. Pregnancy Loss and Iodine Status: The LIFE Prospective Cohort Study. Nutrients. 2019;11(3):534. doi:10.3390/nu11030534.

17. Snart CJP. Keeble C. Taylor E. Cade JE. Stewart PM. Zimmermann M. et al. Maternal iodine status and associations with birth outcomes in three major cities in the United Kingdom. Nutrients. 2019;11(2). pii: E441. doi: 10.3390/nu11020441.

18. Porterfield SP. Hendrich CE. The role of thyroid hormones in prenatal and neonatal neurological development- -current perspectives. Endocr Rev. 1993;14(1):94-106. doi: 10.1210/edrv-14-1-94.

19. Zimmermann MB. Iodine deficiency in pregnancy and the effects of maternal iodine supplementation on the offspring: A review. Am J Clin Nutr. 2009;89(2):668S-72S. doi: 10.3945/ajen.2008.26811C.

20. Olivo-Vidal ZE. Rodríguez RC. Arroyo-Helguera O. Iodine affects differentiation and migration process in trophoblastic cells. Biol Trace Elem Res. 2016;169(2):180-8. doi: 10.1007/s12011-015-0433-1.

21. Gulaboglu M. Borekci B. Halici Z. Placental tissue iodine level and blood magnesium concentration in pre-eclamptic and normal pregnancy. Int $\mathrm{J}$ Gynaecol Obstet. 2007;98(2):100-4. doi: 10.1016/j.ijgo.2007.03.047.

22. Niemeijer MN. Grooten IJ. Vos N. Bais JM. van der Post JA. Mol BW. et al. Diagnostic markers for hyperemesis gravidarum: A systematic review and metaanalysis. Am J Obstet Gynecol. 2014;211(2):150.e1-15. doi:10.1016/ j.ajog.2014.02.012.

23. Morali GA. Braverman DZ. Abnormal liver enzymes and ketonuria in hyperemesis gravidarum: A retrospective review of 80 patients. J Clin Gastroenterol. 1990;12(3): 303-5. doi: 10.1097/00004836-199006000-00014.

24. Pereira AC. Martel F. Oxidative stress in pregnancy and fertility pathologies. Cell Biol Toxicol. 2014;30(5):301-12. doi: 10.1007/s10565-014-9285-2.

25. Fait V. Sela S. Ophir E. Khoury S. Nissimov J. Tkach M. et al. Hyperemesis gravidarum is associated with oxidative stress. Am J Perinatol. 2002;19(2):93-8. doi: 10.1055/s-2002-23554.

26. Ravuri C. Svineng G. Pankiv S. Huseby NE. Endogenous production of reactive oxygen species by the NADPH oxidase complexes is a determinant of $\gamma$-glutamyltransferase expression. Free Radic Res. 2011;45(5):600-10. doi: 10.3109/10715762.2011.564164. 